\title{
Mexico’ s Dual Trade With its Two Main Partners: Integration vs. Approximation
}

\section{Roberto Gutierrez-Rodriguez ${ }^{\star}$}

Department of Economics, Metropolitan Autonomous University (UAM), Campus Iztapalapa, Prol. Canal de Miramontes 3855 , Los Colorines, 14386 Mexico City, CDMX, Mexico

"Corresponding author: Roberto Gutiérrez-Rodríguez Department of Economics, Metropolitan Autonomous University (UAM) Campus Iztapalapa, Prol. Canal de Miramontes 3855, Los Colorines, 14386 Mexico City, CDMX, Mexico, Tel: +525554834000; E-mail: robertogtz@yahoo.com

Rec date: May 30, 2017, Acc date: July 20, 2017, Pub date: July 27, 2017

Copyright: (c) 2017 Gutiérrez-Rodríguez R. This is an open-access article distributed under the terms of the Creative Commons Attribution License, which permits unrestricted use, distribution, and reproduction in any medium, provided the original author and source are credited.

\begin{abstract}
Trade and foreign direct investment (FDI) relations of Mexico with its two major trading partners, the United States of America (USA) and China are addressed. The link with USA dates centuries back; nowadays its reference is the North American Free Trade Agreement (NAFTA), put into operation in 1994. The bilateral Grubel and Lloyd Index (GLI) shows high levels, due to the integration of many industries along both sides of the border. Besides, the trade generates a substantial surplus for the country, combined with important FDI inflows. Relations with China resurfaced after the commissioning of NAFTA (as with other Asian countries interested in approaching the world's largest market and also sell in Mexico's). They are characterized by an excessive unbalance: for every 100 dollars Mexico imports from that country it only manages to export nine, and Chinese FDI in the country is marginal. The bilateral GLI is low, but it has been growing steadily. Although the possibilities of further collaboration seem enormous, in the absence of a comprehensive trade agreement they remain attached to the guidelines of the World Trade Organization (WTO).
\end{abstract}

Keywords: Trade flows; FDI; Integration; Grubel and Lloyd index; Dual trade

\section{Introduction}

The concept of dual trade goes back at least to the sixth decade of the twentieth century, when in his attempt to explain the modus operandi of the technological gap theory spread it to more than two countries and noted that some of them sent exports based on technology gap to less developed partners and on low wages to developed ones [1]. Evidently the conventional theory (the HeckscherOhlin model, H-O) did not provide for this.

In applying this observation to his own country and combining it with the product life cycle [2-4] noted. Greece was competitive in capital goods to the Middle East and standardized goods to the countries of Western Europe-this being a step forward in the process of reviewing the theory which was initiated by the so-called Leontief paradox.

Is by virtue of such works, along with those of [5-8] that a new approach was put in place emphasizing that the engine of international trade lays not on the supply side, but in demand's. At the same time it was argued that approximately three-quarters of international trade of merchandises was not carried out in conditions of perfect competition and constant returns to scale, but in those of oligopoly and increasing returns to scale-then laying the foundations for the so-called New International Trade Theory (NITT).

Looking at the pattern of industrial development of Japan ant its leading role in the advancement of the East Asian region, different scholars from that side of the world have found similarities between the Japanese-East Asian industrialization process, associated to the flying-geese path [9] and the product life cycle theory.
It is clear that the flying-geese paradigm was conceived on the basis of a Japanese economy advancing rapidly towards industrialization during the last part of the 19th century and the early years of the postwar period. The process was based on its extensive production of manufactures (with a notorious lack of markets to export them during the interwar period) and the accelerated development of its arms industry, combined with its conspicuous need for natural resources. The theories of the product life cycle and the technology gap (both known as neo-technology theories), emerged when the limitations of the $\mathrm{H}-\mathrm{O}$ model became evident and even the Korean War had concluded.

On the above grounds, some Asian scholars have found similarities between the flying-geese path and the neo-technology theories, particularly the product life cycle, as means to explain the rapid industrial development of the first quartet of economies that followed Japan in the East Asian region: Singapore, Taiwan, Hong Kong and South Korea. Later on they suggested that China's expansion was based on ties and influences that these four followers exerted on it, as described $[10,11]$.

A feature of most newly industrialized economies of that region are their intense trade relations with Japan during the postwar period. Then they procced to have a great deal of trade among themselves, and simultaneously with the rest of the world. This multi-connection, successful at both regional and global levels, concomitant to the industrialization process and with high competitive levels [12] has been translated into extraordinary trade surpluses. Such particular benefits of inserting in the global economy have not been equally evident in regions that simultaneously or a few years later embarked in open trade programs, i.e., the Manufacturing Exports Promotion Model (MEPM) in the way it was conceptualized by the international financial institutions [13]. 
A case in point is Mexico, which displays contrasting results with its two main trading partners. With the largest economy in the world, it has a conspicuous trade surplus, especially ever since NAFTA was put into operation in 1994. In addition, major trade flows toward and from the USA are composed by manufactures, giving rise to a high level of cross-border integration in terms of the GLI. In addition, FDI from the USA to Mexico is the highest of all countries, although it has remained stagnant for several years.

China, whose level of industrial development is closer to Mexico's but enjoys a rate of economic growth three times higher, exerts an enormous pressure on the Mexican economy, as this has to deal with an abnormal and growing trade deficit with the former. In addition, bilateral trade flows are differentiated and traditional in essence, since the main purchases of Mexico are Chinese manufactures, in large quantities, and predominantly sells to that partner raw materials and low-labor skilled manufactures, in small amounts. As a corollary, levels of integration between both economies' industries are low, but have grown in recent years, and FDI is exceptionally limited.

To analyze this, the essay proceeds in the following way. The first section examines trade flows Mexico-USA and Mexico-China over the past 22 years, the point of departure of China's reinforced trade with Mexico. In the process, it passes through the implementation of NAFTA in 1994, and China's accession to the WTO in 2001, which effects on Mexico's bilateral trade with both partners are essential.

The second section analyses the degree of integration of the Mexican manufacturing industry with those of the USA and China as determined by the level of Bilateral Manufacturing Intra-Industry Trade (BMIIT), measured through the GLI. By this means, deep disparities are observed in the integration levels with both economies, despite the fact that Mexico-China's BMIIT has tended to grow over the past 22 years.

The third section explores the reception of Mexico's FDI from its two main partners, making it clear that in this area the differences are striking and that in case the presence of Chinese capital in the Mexican manufacturing sector remains low, industrial integration will not evolve as desired discouraging the signing of a bilateral and comprehensive trade and investment agreement. Finally, conclusions are presented.

\section{Trade flows}

Due to its geographical position, its market size and its productive capacity, the USA has been the main trade partner of Mexico since the second quarter of the 20th century. China began to gain importance only at the beginning of the 1990s, when Mexico embarked in a policy of openness implemented in 1985 by means of an important tariff dismantling process. This continued with its accession to the General Agreement on tariffs and trade (GATT) in 1986, and with the negotiation of NAFTA with the USA and Canada, put into operation in 1994.

In 2001 China joined the WTO, action to which Mexico initially opposed great resistance, and soon moved to the position of second trading partner of this country, taking the place of Spain. It also prevented Canada to ascend to that position, taking currently the third place. Figure 1 shows the extraordinary rise of total trade (exports plus imports of goods; top dark line) of Mexico with the world, which raised to almost 800 billion dollars in 2014. Out of that amount, 514 billion were traded with USA, 72 billion with China and 211 billion with other countries.

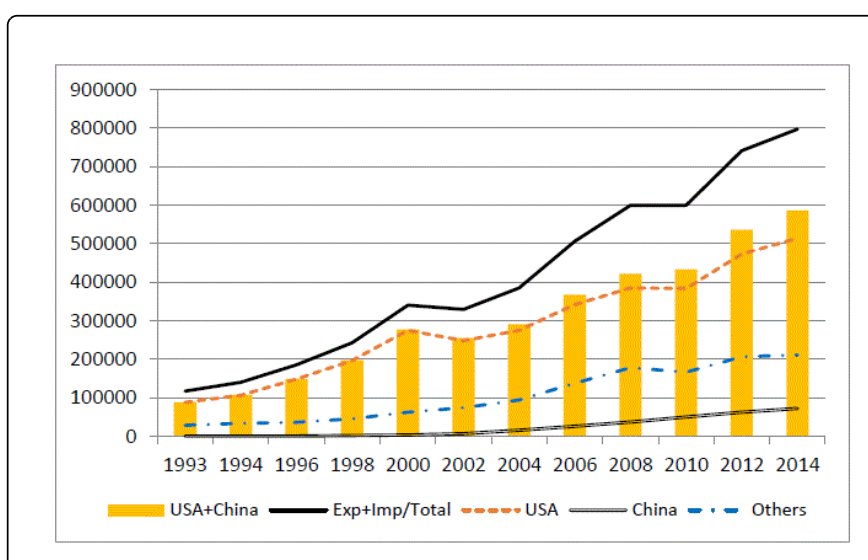

Figure 1: Total trade of Mexico with USA, China and the rest of the world 1993-2014 (Source: Elaborated on the bases of Ministry of Economy-2015).

Figure 2 shows that Mexico's total trade with the world grew between 1993 and 2014 at an annual average rate (AARG) of 10.1\%; with USA at $9.2 \%$, and with China at $29.2 \%$-for the moment the latter being the most dynamic. It is also observed that, although in 2014 nearly two-thirds of Mexico's total trade was carried out with USA, China had grown so fast that became responsible for $9.1 \%$.

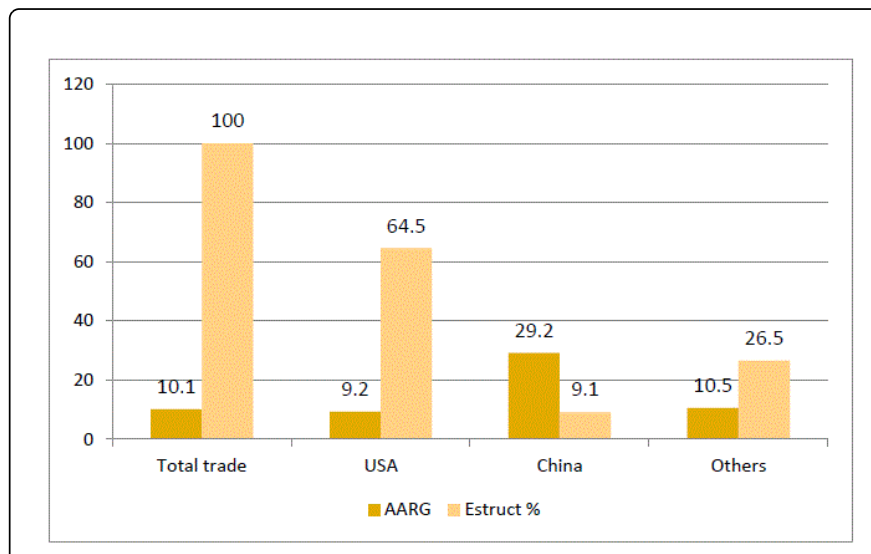

Figure 2: Mexico's trade structure and rates of growth 1993-2014 with its two main partners, (Source: Elaborated on the bases of Ministry of Economy-2015).

By regions, the contrast between the trade surplus of Mexico with the USA and Latin America together in the period is surprising (nearly 135 billion dollars altogether by 2014, as shown in the graph 3) in comparison with the increasing deficit with other regions, particularly the East Asian (almost 93 billion dollars). These include China, Japan, and Newly Industrializing Countries (NICs): South Korea, Hong Kong, Singapore and Taiwan. The situation is exacerbated by the persistent deficit, although apparently more controlled, with all European countries as well as the group Rest of the World. 


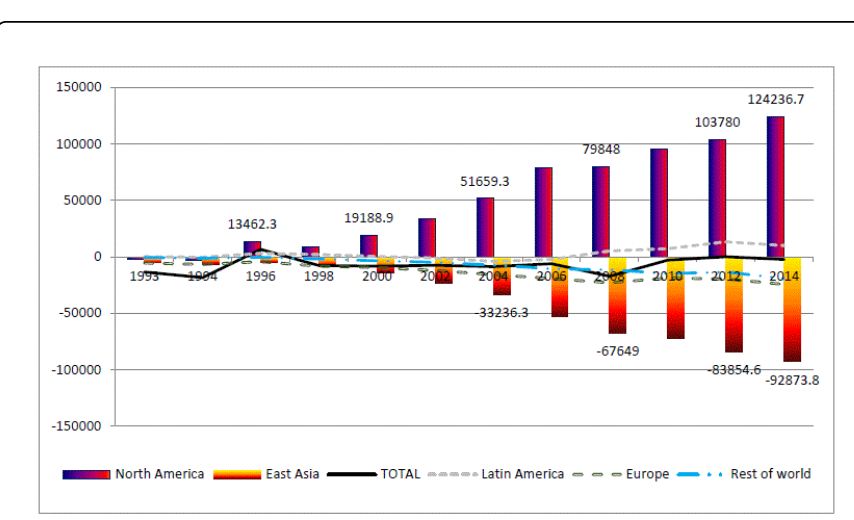

Figure 3: Mexico's Trade balance by regions, (Source: Elaborated on the bases of Ministry of Economy-2015).

Obviously the great contradiction of Mexico's foreign trade with its two main partners is that while with the USA it exhibits a rising trade surplus ever since NAFTA operations started, its balance with China is increasingly negative. This is reflected by the fact that, for every 100 dollars Mexico imports from that country, it only manages to place 9 (2014 Figures). This explains why, in terms of exports, the second trade partner of Mexico is not China, but Canada.

As shown in Figure 4, while Mexico's trade balance with the world is hardly less than zero (solid line), the surplus with the USA reached 124 billion dollars (dashed line) in 2014 out of which 60 billion, almost half the total, were used to cover its shortfall with China (double line which turns rapidly negative in view of tariff reciprocity factors associated with its entry into the WTO in 2001). One additional issue to consider is that costs of imported inputs and parts for the so-called maquila industry are lower when fetch in China than in the USA and other developed countries.

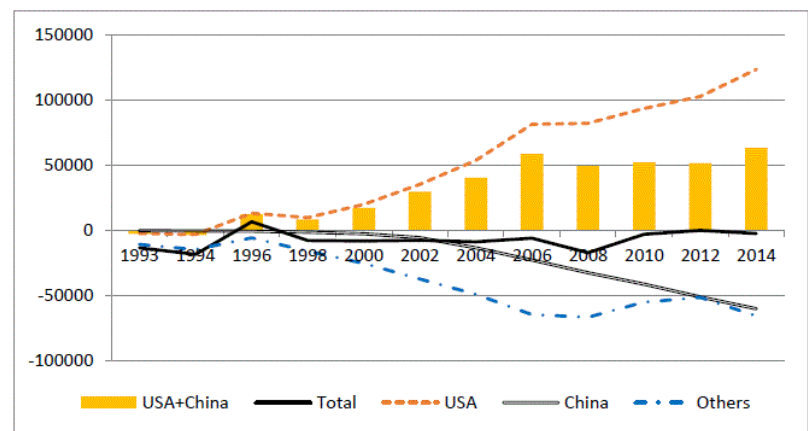

Figure 4: Mexico's trade balance of Mexico with its two main partners, (Source: Elaborated on the bases of Ministry of Economy-2015).

Therefore, the sum of Mexico's trade balance with the USA and China (solid bar) fluctuated in the range of 50 thousand dollars to 63 billion dollars between 2006 and 2014. A similar pattern was shown by the group Other Countries (dots and dashes line), up to the Great Recession of 2008-2009. Mexico managed to reverse it, at least until 2012, thanks largely to its competitiveness in the automotive and electronics industries, this resulting in surpluses with countries like
Brazil, Argentina and Chile, its three major trading partners in Latin America. The same is true for Colombia, a country with which the surplus has been persistent all along the century, but not for Costa Rica, which supplies microprocessors to computer-producing companies established in Mexico-the more such companies increase their exports from Mexico, the more they import microprocessors from Costa Rica, where Intel has two plants established.

And if China has entered with great speed to the Mexican market, the same thing has done, but in a magnified way, with the USA. So, a few years after its entry into the WTO it displaced Mexico as USA's second commercial partner. After the Great Recession Mexico managed to revert part of the loses and, as it can be seen in table 1, in 2010 was responsible for $13.5 \%$ of the USA total trade, slightly below the $14.9 \%$ achieved by China. However, in terms of total exports to that country, China is responsible for almost $20 \%$, followed by Canada, with $14.7 \%$, and then Mexico with $12.5 \%$.

\begin{tabular}{|l|l|l|l|l|l|}
\hline Position & Country & Exports & Imports & $\begin{array}{l}\text { Total } \\
\text { trade }\end{array}$ & \% in total \\
\hline & All countries & $1,623.30$ & $2,345.80$ & $3,969.10$ & 100 \\
\hline 1 & Canada & 312 & 346.1 & 658.1 & 16.6 \\
\hline 2 & China & 124 & 466.7 & 590.7 & 14.9 \\
\hline 3 & Mexico & 240.3 & 294.2 & 534.5 & 13.5 \\
\hline 4 & Japan & 67 & 133.9 & 200.9 & 5.1 \\
\hline 5 & Germany & 49.4 & 123.2 & 172.6 & 4.3 \\
\hline 6 & South Korea & 44.5 & 69.6 & 114.1 & 2.9 \\
\hline 7 & United Kingdom & 53.9 & 54 & 107.9 & 2.7 \\
\hline 8 & France & 31.2 & 47 & 78.2 & 2 \\
\hline 9 & Brazil & 42.4 & 30.3 & 72.8 & 1.8 \\
\hline 10 & Taiwan & 26.8 & 40.6 & 67.4 & 1.7 \\
\hline Source: US Department of Commerce (2012) & & \\
\hline
\end{tabular}

Table 1: Mexico's total trade with the U.S. and major trading partners in 2010

\section{Level of Industrial Integration}

Besides the duality trade surplus with the USA-growing deficit with China, there is another contrast highly explained by the previous, and it is that as a strong exporter of manufactures Mexico and China are rivals not only for the USA market but also for that of Mexico. Such a duality is explained by the fact that while the domestic industry has reached a high degree of integration with that of the USA, measured in terms of the GLI, by any point of view it has managed to integrate to the Chinese one. That is why $80 \%$ of bilateral trade is traditional, i.e. $\mathrm{H}$ O type.

Clearly there are two factors that favor this. The first is the geographic proximity of Mexico with the USA vis-a-vis the distance with China. The second is the existence of NAFTA, whit nominally zero tariffs between its three partners, versus a complete absence of trade agreements with China, whose tariff policy is set to winch allowing the WTO. Although both countries have signed multiple agreements on trade and related areas, especially after mutual 
Presidential visits in 2013 and 2014, the deepest documents date from previous years and address the prevention of tax evasion and the protection of investments: Agreement to avoid double taxation and prevent fiscal evasion in respect of taxes on income (DOF 2006), and Agreement for the promotion and reciprocal protection of investments (DOF, 2009).

If other commercial issues with China are added, it is possible to see a not entirely flattering panorama for bilateral negotiations. On the side of the incoming trade, there are recurrent complaints of Mexican industrialists with regard to the smuggling of Chinese products and merchandises, such as clothing, footwear, toys, bicycles, appliances, steel sheets and tubes, and electrical and electronic equipment. Some of them where subject in 2015 to import controls depending on the investigation process-bicycles, a definite compensation tax of 13.12 dollar per unit, and steel sheets a provisional compensatory quota ranging $72.16 \%$ to $78.96 \%$.

On the side of the outgoing trade, the discovery of clandestine sales of iron ore by Mexican traffickers to Chinese traders during the period 2008-2013, when its price was at its highest level, embarked in the port of Lázaro Cárdenas, Michoacán, prompted the federal Government to transfer its administration to the Mexican Navy, in 2013. During the following year, and for the sake of ecological preservation, the Government cancelled a project of commercial mega center known as Dragon Mart, which was being built with Chinese capital in Cancun, the most important tourist destination of the country. And just a few months later, in early 2015, it became known that due to budget cuts driven by the fall in the international price of oil, which accounted then for $30 \%$ of fiscal revenues (nowadays they account for $15 \%$ ), the Government ordered the definite cancellation of the high-speed train Mexico-Queretaro project, for which the technological partner and constructor was the Chinese enterprise China Railway Construction Corporation. That is the second largest railway constructor company of China and the first contractor of railway projects around the world, under the supervision of the Council of State of the People's Republic of China. The Chinese Government announced in May, 2015 that the company would receive a compensation by part of the Mexican Government of 20 million pesos ( 1.3 million dollars at the prevailing exchange rate), but the same notice was only made public in Mexico one month later.

In this way the rapprochement with China, not only in the commercial field but also on that of physical investment, has had ups and downs and been largely casuistic, affecting the possibility to become a serious rival to USA investment. This led different observers to predict since long ago the possibility that as business goes forth, relations be put in a position of open confrontation [14].

In relation with trade integration, Weighted AverageIndex (WAGLI) is presented in Figure 5 which refers to Mexico-USA trade and Mexico-China trade on the bases of five-digit Standard International Trade Classification (SITC) for the period 1983-2006 [6]. This index, which measures two-direction trade between two countries or groupings, known as Intra-Industry Trade (IIT), can be calculated at different levels: section (single-digit), division (two-digit), group (three-digit), subgroup (four digits) and item (five digits). Obviously more disaggregated information accounts for greater reliability of the results, and as a consequence the level of the index tends to be lower. It takes values ranging from 0 to 1 . For didactic purposes, the results tend to be multiplied by 100 and presented as percentages. A value of zero means that the degree of integration is non-existent; a value of 1 (or $100 \%)$ implies that the integration is absolute [2].
By Convention, it is accepted that a 0.5 (50\%) or greater GLI means a very high level of integration among the industries of the countries analyzed. When those sort of values are found in pre-liberalization stages, commercial authorities of the countries involved feel compelled to proceed with formal integration, then signing integration or free trade agreements without regard to any possible differences in the levels of development of the countries involved. A high GLI suggests them a considerable degree of trans-frontier economic integration, then minimizing the need to implement measures to mitigate the loss of market of producers in one or more partners [3]. Conversely, if the GLI is very low and tariffs have been reduced due to the membership of those countries to regional integration schemes or to the WTO, it is possible that support measures are required to prevent the disappearance of most affected activities, especially in the less competitive country or countries of the group.

Figure 5 shows that, at the level of annual weighted averages, the Mexico-USA Manufacturing GLI (MGLI) was rather close to $50 \%$ after the implementation of NAFTA. Therefore, the authorities of the country expected no damage to domestic producers and felt it was no necessary to put into practice mitigation measures. This was a first blow to the textile, clothing, footwear, furniture, and toy industries, and outside the manufacturing sector meant a serious threat to corn, beans, chicken and pork producers. Interestingly, after an upward trend of the MGLI initiated in 1990, approaching 50\% in 1994, it started to retreat through 2006 and further years, as shown by the fivedigit SITC calculations reported by the Government of Mexico to the Latin American Association of Integration [14]. This generated concern to many scholars, as can be understood as a reversal in the achievements of the integration process.

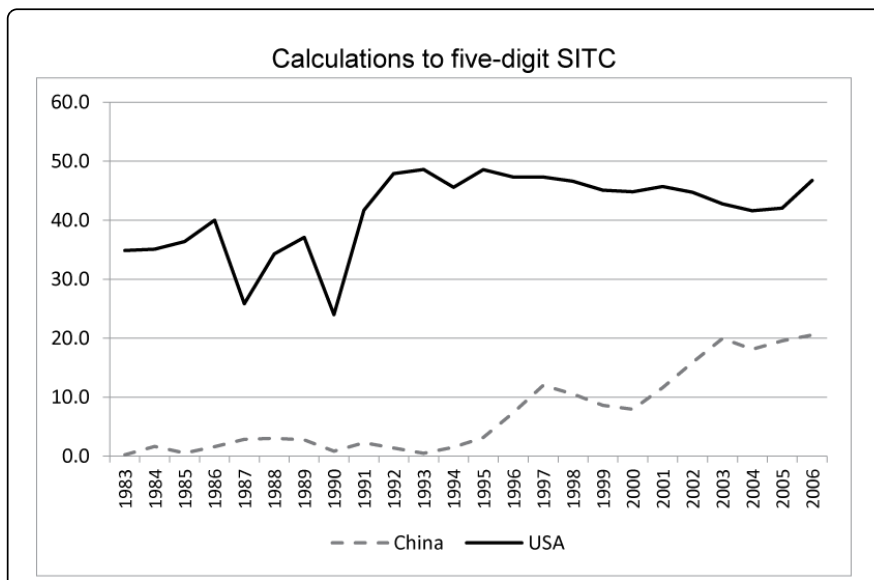

Source: On the bases of ECLAC figures (2010)

Figure 5: Grubel and Lloyd Index Weighted Average of Mexico with USA and China in \% (source: On the bases of ECLAC Figures 2010)

Things worsened for the same manufacturing industries when China joined the WTO, with lower production costs than those of the USA and appealing to the consumption of standardized products. However, it must be recognized that most of the IIT is vertically differentiated (VDIIT), i.e., trade of intermediate products rather than products for final consumption. This meant a double blow to domestic producers. In addition, Chinese industrialists were able to penetrate successfully in the markets of parts and materials demanded by multiple branches which had been closely integrated for years to their American counterparts, in particular the automotive, auto-parts, 
electric and electronic industries, responsible for more than $50 \%$ of Mexico-USA trade.

In more detail, the highest levels of integration between Mexico and the USA have been associated during many years with SITC section 7 , machinery and transport equipment, with an unweight GLI that for example in 2006 was higher than 96\%. This category includes divisions 75 , Office machines and automatic data processing machines; 76 , Devices and equipment for telecommunications and recording and reproduction of sounds; 77, Machinery, equipment and electrical appliances NES and its parts and electrical parts (including not electric counterparts NEP of the electrical household equipment); and 78, road vehicles (including hovercraft).

At the time the integration with the USA was weakening, an important advance in the level of integration of the manufacturing sectors of Mexico with China began-the MGLI raised from less than $1 \%$ in 1993 to $10 \%$ in 2001 , and just over $20 \%$ in 2006 . Calculations using the harmonized system show that bilateral IIT items with levels greater than $50 \%$ are minority $(31 \%)$ and the highest IIT belongs to the auto-industry, with a near $60 \%$ unweighted IIT (though if the primary sector is taken into account it can be seen that in food products and live animals the index has reached up to 94\%). Within the autoindustry, engines have the most important role in such an index, and exports of parts and accessories are quantitatively the most important. Companies that have contributed most to this respect are General Motors, Chrysler, Ford, and Volkswagen [14]. Keep in mind, however, that the industry that weighs more on bilateral trade is that of information and communication technology (ICT).

The IIT with China, unlike that carried out with the USA, generates a strong trade deficit; however both flows refer to vertically differentiated low-quality intra-industry trade (VDLQIIT). That means that the unit price of goods exported by Mexico represent $85 \%$ or less of the price of the same product when it is imported by the country (slight differences of quality may be also involved). This means for Mexico renouncing to technological innovation competition and focusing on labor cost competition. The application of this criteria to bilateral trade with the USA can be reasonable for the short and medium term, but in doing so with China's trade a clear absence of a science and technology policy and, more generally, of an industrial policy comes to mind [4].

The distance between Mexico and China, the low bilateral FDI, the disproportion between imports from China and exports from Mexico, the absence of a free trade agreement between both countries, and the different conceptualization they have about trade opening (Mexico is open to imports; China and in general Asian countries stimulate exports) will sooner than later put a halt to the GLI growth, however the progress of the past 20 years [5].

\section{Foreign Direct Investment in Mexico}

From 1999 to 2014 FDI in Mexico amounted to 389,640 million dollars, with an annual average of 25,976 million dollars. Structurally, $46 \%$ corresponded to USA, $0.1 \%$ to China and the remaining $53.9 \%$ to other countries, highlighting four: The Low Countries, Spain, Canada and Belgium. In the period the average annual growth of incoming FDI from USA decreased at a rate of - $9 \%$, while that of China, which was just 70 million dollars in 2014 (see Figure 6), increased 20.7\%, and that of other countries $6.8 \%$. Given the fact that FDI usually supports integration of national vis-à-vis international branches of economic activity, it comes with no surprise that the MIIT with the USA has decreased slightly in the period, as already explained, while increasing that with China.

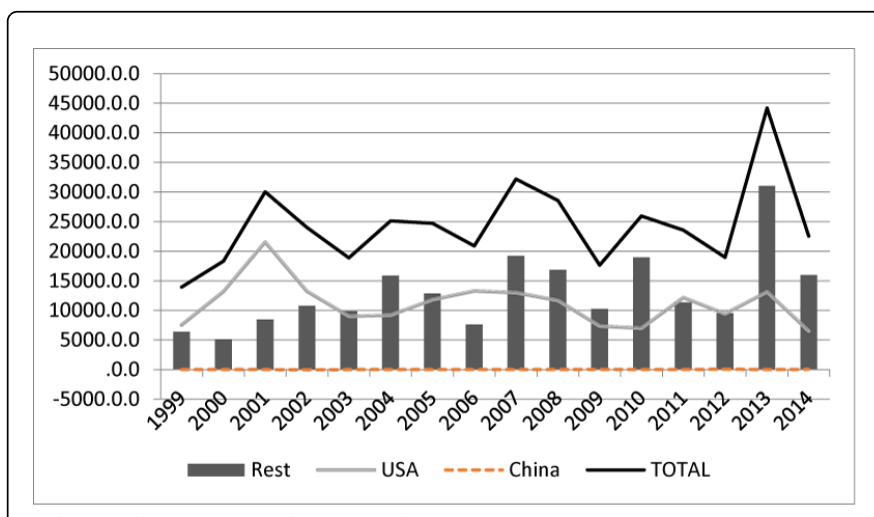

Source: On the bases of Ministry of Economy (2015)

Figure 6: Total FDI to Mexico 1999-2014.

Figure 7 shows that the category that has contributed the most to FDI of USA in Mexico from 2006 on has been that of profits reinvestment (values represented by the solid low line) while new investments have exhibited a downward trend, to become negative in 2014. The main reception sectors have been commerce and manufactures, including export maquila industry.

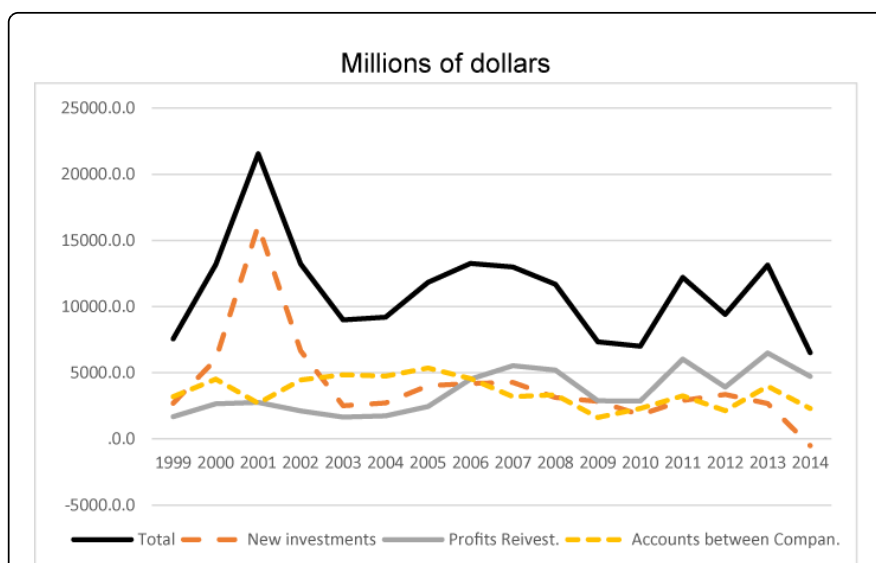

Source: On the bases of Ministry of Economy (2015)

Figure 7: FDI from the USA to Mexico, 1999-2014.

With regard to China, FDI is composed mostly by new investments (Figure 8), focusing predominantly on the commercial (43.2\%) and manufacturing sectors (34\%), including maquila industry. 
Page 6 of 8

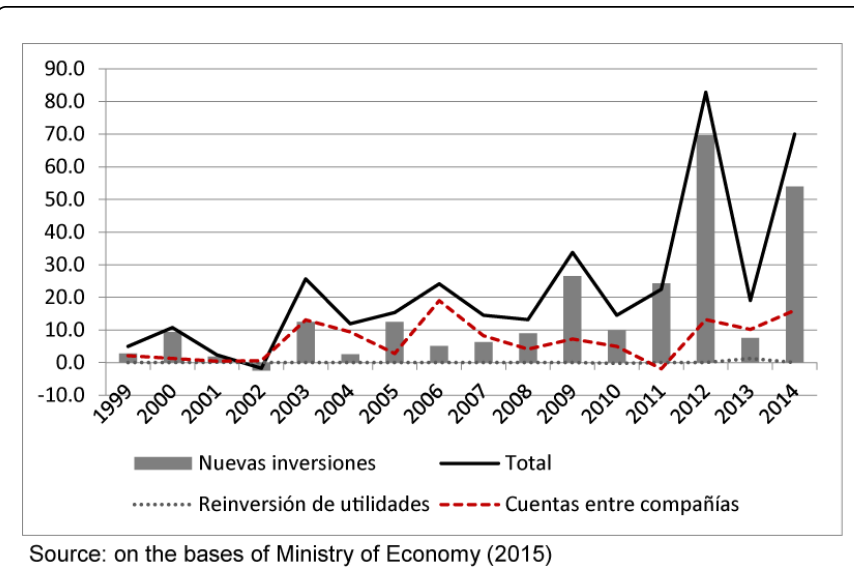

Figure 8: FDI from China to Mexico, 1999-2014.

Cross-sectional studies show a close relationship between FDI and the MIIT index. In a study by pairs of 23 emerging manufacturing countries with their main trading partner (in 22 of the 23 cases a developed country) this author found evidence of a direct relationship between the MIIT index of every pair of countries with the natural logarithm of the net balance of FDI of the emerging country, as it is shown in Figure 9.

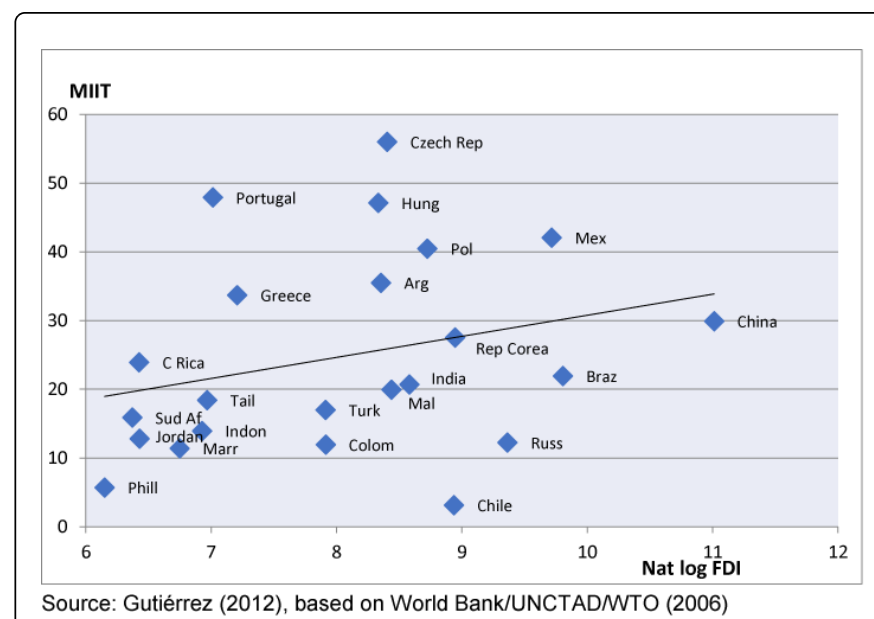

Figure 9: Relationship between the MIIT index and the natural logarithm of the net balance of FDI in 23 emerging countries in 2005.

\section{Trade Policy Consequences}

The commercial opening of Mexico in the 1980s (dismantling of tariff barriers in 1985, before its accession to the General Agreement on Trade and Tariffs, GATT) and its transition to the Manufacturing Exports Promotion model (PME) gave the country the opportunity to evaluate for the first time the importance of acquired comparative advantages. This, along with its commercial and investment integration to USA as from the beginning of 1994 , resulted in a clearly dynamic GLI until 2000, enhanced by the reception of FDI.

The stalemate in the bilateral GLI started in the 2001-2002 Information and Communication Technologies (ICT) recession. Some observers thought in those years that, to the extent that Mexico managed to sign free trade agreements with more economies, the participation of IIT in total trade would tend to grow. Partly because of this, at the beginning of the 21 st century Mexico came to be the country with the largest number of partners involved in trade agreements.

However, the weight of new trade agreements was not enough for the GLI with the world offset the fall with the USA, as shown in Figure 10. This puts in clear terms that the advances of Mexico in trade diversification have not translated into greater industrial integration. Empirical evidence suggests that this is due to the fact that increased manufacturing trade have not been combined with greater FDI in the manufacturing sector, the reason being that, as such investment grows Mexico has the opportunity to exploit competitive advantages associated whit VDLQIIT. The clearest example is China, which shortly after entering the WTO in 2001, became the second trade partner of Mexico, so that the adding of Mexico-China and Mexico-USA trade flows account for three-quarters of the country's total trade. But as Chinese FDI in the country's manufacturing sector is low so it is Mexico-China IIT.

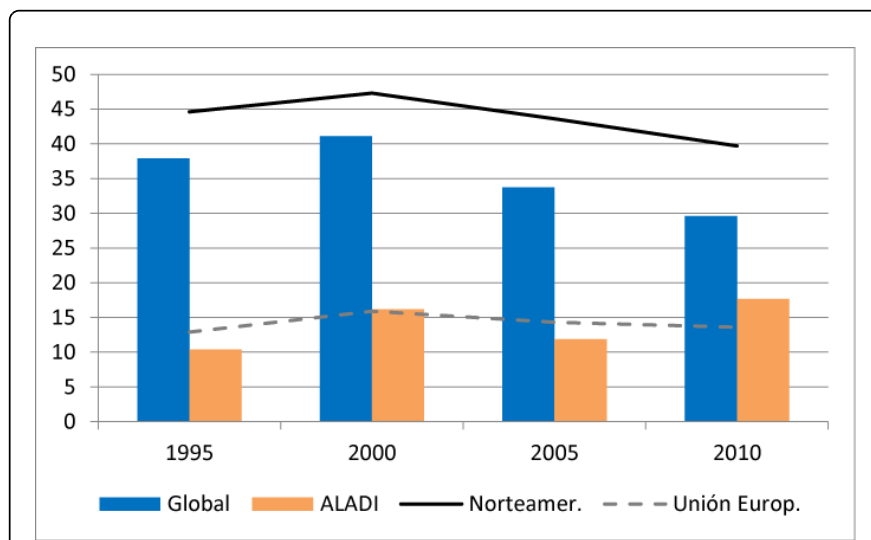

Source: ALADI (2012)

Figure 10: IIT of Mexico by regions to five-digit SITC in \%. Conclusions and Suggestions

Departing from a 45 years ago Greece's dual model adjusted to current conditions, Mexico exports to China predominantly labor intensive products, ranging from raw materials (crude oil, minerals, fruit) to manufactured and semi-manufactured products (automotive parts, some automobiles and tequila), and imports in a growing manner manufactures with medium and high technological content, in particular parts and assemblies for the ICT industry, computer equipment, capital goods, car engines, some automobiles, mechanic tool and the like $[15,16]$. In contrast, most of its trade relations with the USA are grounded in the manufacturing sector, especially the automotive, auto parts, electric and electronic industries, being the main characteristic of the underlying trade flows their intense two-way relation.

This means essentially that Mexico holds two divergent types of commercial relations with its two main trading partners, which contradicts the basic assumptions of neoclassical theory of international trade and even poses difficulties to the NITT $[5,7,8]$. On the one hand, with China trade is by far of interindustry type, a-la $\mathrm{H}$ - 
O. On the other hand, with USA is predominantly of intra-industry kind, based on acquired comparative advantages.

This seemingly suggests that the commercial duality of Mexico is comparable today which that exhibited 50 years ago by Greece with its trading partners in the Middle East in the one hand, and in Western Europe in the other, however the differences of products and levels of integration. The most significant element of this comparison is the ability acquired by Mexico to hold at the same time traditional trade flows with a group of partners, based on comparative costs a-la $\mathrm{H}-\mathrm{O}$, and intra-industry trade flows with others on the bases of acquired competitiveness mostly of intermediate consumption goods (goods for production purposes), as originally noted by Ethier [15]. Nowadays this tend to happen to more emerging economies as they engage heavily in international trade.

Given the previous duality, along with the fact that the MEPM increasingly offers less possibilities for Mexico to advance in international markets, the question that arises is: what actions can contribute to unblock the impasse in which the country's manufacturing IIT is? Obviously one rather important is the strengthening of trade and investment relations with East Asian countries, which bilateral relations, exception made of Japan, are not governed by agreements or comprehensive treaties [16-20].

Until mid-2015, the only countries in such a region which hold formal approaches with Mexico, measured in terms of a series of partial and for-the-case agreements, were China and South Korea. The first responded to contacts between high level officials from both countries, particularly the Presidents, (years 2013 and 2014), though some were carried out during 2008 and 2009. They comprise the following fields: mining cooperation, mutually agreed commercial solutions, defense and commercial remediation, support to emerging industries, promotion of investment, industrial cooperation, and normalization of relations [21]. The agreements with South Korea cover the fields of mineral resources, small entrepreneurs, small and medium enterprises, and scientific and technical cooperation.

The situation changed during the last quarter of 2015 , when the Presidents and heads of Government of 12 countries that border the Pacific basin signed the Trans-Pacific Partnership (TPP), the countries being: Canada, USA, Mexico, Peru and Chile, on the side of America, and Japan, Singapore, Malaysia, Vietnam, Brunei, Australia and New Zealand, on the Asian side. Obviously for Mexico the main problem is that the document excludes three important partners: China, the second in importance; South Korea, the sixth, and Taiwan, the eight. The joint trade deficit with them accounted in 2014 for 78 billion dollars, equivalent to nearly two-thirds of the surplus that Mexico had in that year with USA (124.2 billion dollars). Conversely, with some countries included in the agreement trade relations are cramped, particularly Brunei, Singapore, Australia and New Zealand. Joint flows between México and them were close to 6 billion dollars in 2014, scarcely $0.75 \%$ of Mexico's trade with the world.

Experience shows that in the quest for rapprochement with East Asia, Mexico should try not to replicate the model of trade agreements that knows and has implemented with its partners in the Western Hemisphere, since the views and priorities of both groups are different. First of all, in Mexico and the rest of Western countries more credibility is given to the market as a regulatory mechanism than in East Asia, to the extent that during three decades Mexico has put aside its industrial policy. Secondly, trade liberalization in Mexico is understood as the dismantling of the tariff and non-tariff protection system; in East Asia the strategy remains to promote exports through different public policies-access to credit, access to technology, access to foreign currency, reorientation of educational priorities, training and retraining of the workforce [12]. Third, the interests of physical investment coming from the countries of East Asia, particularly from China, seem to focus on sectors with limited technological spillovers and little prospect of industrial integration-commerce, food, and supply of raw materials. Virtually all calculations on IIT made for East Asian countries show that true integration between industries of that area tends to be intra-regional. Therefore the challenge for outside manufacturing exporters, including Latin America as a whole, consists of developing capabilities to offer not only Japan, but also China, South Korea, Taiwan and Singapure products as competitive as those they receive from Malaysia, Indonesia, Thailand, Philippines, Vietnam, India and Bangladesh. This implies challenging technological, managerial and financial efforts that perhaps are huge in the short term, but not insurmountable in the medium and long, and for which the flow of Asian FDI towards the most competitive sectors could play a leading role.

\section{References}

1. Hufbauer Gary C (1966) Synthetic Materials and the Theory of International Trade. Cambridge: Harvard University Press, p: 165.

2. Vernon R (1966) International Investment and International Trade in the Product cycle. Quarterly Journal of Economics 80: 190-207.

3. Wells JR (1968) A Product Life Cycle for International Trade? Journal of Marketing 32: 1-6.

4. Linder Staffan Burenstam (1961) An Essay on Trade and Transformation. John Wiley and Sons 70: p.

5. Grubel HG Peter J Lloyd (1971) The Empirical Measurement of IntraIndustry Trade. The Economic Record 47: 494-517

6. Krugman PR. (1979) Increasing Returns, Monopolistic Competition, and International Trade. The Journal of International Economics 9: 469-479.

7. Lancaster Kelvin (1980) Intra-Industry Trade under Perfect Monopolistic Competition. Journal of International Economics 10: 151-175.

8. Akamatsu, Kaname (1935) The Trade Trend of Woolen Products in Our Country. Review of Business and Economy.

9. Hsieh, Kuan-Yu (2012) A Questioning on the Adaptability of FlyingGeese Pattern of Industrial Development among Countries in the 21st Century. Meijo Asian Research Journal 3: 3-18.

10. Hsieh KY, Yuri Sadoi (2012) Changes in Triangular Economic Relations between Japan, China and Taiwan in the 21st Century. MARC Newsletter 13.

11. Stiglitz Joseph E (1996) Some Lessons from the East Asian Miracle. The World Research Observer 11: 151-177.

12. www.worldbank.org

13. Cardenas Castro, Lorena, Enrique Dussel Peters (2011) Trade intra industrial in Mexico: a comparison between China and the United States. Trade Exterior 61.

14. Mousouris, Sotiros G (1972) Manufactured Products and Export Markets: Dichotomy of Market for Greek Manufactures. Wells Jr pp: 193-221.

15. Ethier Wilfred J (1982) National and International Returns to Scale in the Modern Theory of International Trade. American Economic Review 72: 389-405.

16. Flying Geese Pattern of Industrial Development in Our Country Japan -Case of Machine \& Tools. Review of Hitotsubashi University 38.

17. Renato Baumann (1998) Economic Commission for Latin America and the Caribbean (ECLAC). FOREIGN INVESTMENT IN BRAZIL AND THE INTERNATIONAL FINANCIAL MARKETS pp: 1-34.

18. Promulgation decree of the agreement between the Government of the Mexican United States and the Government of the People's Republic of 
Citation: Rodriguez (2017) Mexico's Dual Trade With its Two Main Partners: Integration vs. Approximation. J Glob Econ 5: 254. doi: 10.4172/2375-4389.1000254

Page 8 of 8

China for the avoidance of double taxation and prevention of Fiscal Evasion in respect of income taxes. Federation's Official Journal.

19. Promulgation decree of the agreement between the Government of the Mexican United States and the Government of the People's Republic of China for the mutual protection of investment promotion.
20. Gutiérrez R, Roberto (2014) The Dual Character Of Foreign Trade In Mexico With Sus Main Commercial Partners. UAM-Bulletins.

21. Roberto Gutiérrez R (2012) The North-South Intra-Industrial Trade: Theoretical and Empirical Elements of the Relationship of Emerging Manufacturing Economies with Developed Countries. 